The returns and computer district information system lists were checked by us after six months. It was clear that, although the average rate of surgical deaths had continued its previous trend, the number of eligible returns was very variable. The returns from one unit were as expected for the first three months and then tailed off rapidly. The only returns from the other unit were for two months in the middle of the six month period. The computer lists were equally poor, identifying only about half of the eligible deaths notified in the returns. The results of the follow up were disappointing and illustrate the problems inherent in implementing and maintaining an accurate audit system. Manually compiled audit systems depend on the knowledge, understanding, and motivation of the staff involved. In this instance, coding clerks have the appropriate skill and can undoubtedly perform well if they understand the problem and receive the medical records immediately after death. However, interest and performance in any task is likely to diminish with time so that a manual system of the type set up in this district will continue to work only if there is regular feedback and monitoring.

\section{RELIABILITY OF COMPUTER BASED SYSTEMS}

In theory computer systems should be reliable. However, systems like the patient information system or district information system in this district depend on complete and accurate coding by the same clerks who complete the NCEPOD returns and are therefore subject to the same problems. Even if all the required data are entered and the patient information system or district information system record contained a large number of data fields, few of them (other than patient name, number, consultant, etc) could be used to generate lists for audit. It proved difficult to pro- gramme the system to generate a list based on, and containing, the data items required by NCEPOD. Newer ward based computer systems being installed as part of resource management initiatives may have advantages. Data on patients will be entered sequentially, much of it by clinical staff, so that as the patient's stay progresses all the relevant data items (date of procedure, surgeon, etc) will be added.

With such systems it should be possible automatically to check the records of any patient dying in hospital for eligibility for the national inquiry and to generate a complete report. Some of the newer systems can also code automatically (for example, for Office of Population Censuses and Surveys, ICD, and Read classifications). Until such systems are widely available, however, timely and accurate coding and entry of all relevant data by well trained and motivated staff remain the key to successful audit.

Provider units are advised to check current methods of reporting to NCEPOD. Managers and clinicians are also advised to check the specification of proposed computer based clinical or patient information systems to ensure they have adequate fields for clinical data and that these can be used to generate reports suitable for the national inquiry or any other audit process.

We thank Dr Sue Atkinson; consultant staff in the surgical specialties, anaesthetics, and pathology; the information and records staff in Lewisham and North Southwark district and Peter Drury, London School of Hygiene and Tropical Medicine, for their help.

1 Buck N, Devlin HB, Lunn JN. Report of a confidential enquiry into perioperative deaths. London: Nuffield Provincial Hospitals Trust, King's Fund, 1987. 2 Protocol for the National Confidential Enquiry into Perioperative Deaths. London: National Confidential Enquiry into Perioperative Deaths, 1988

(Accepted 10 April 1992)

\title{
Value of routine ultrasound scanning at 19 weeks: a four year study of 8849 deliveries
}

\author{
Carole A Luck
}

\begin{abstract}
Objective-To evaluate the effectiveness of routine ultrasound scanning at 19 weeks' gestation in an unselected population in terms of accuracy of detection of fetal structural abnormality and the effect on obstetric and neonatal care.

Design-Prospective study over four years. Scans performed by radiographers with overall supervision by a radiologist.

Setting-Ultrasound department of district general hospital.

Subjects - All pregnant women were offered scans; 8523 of $8849(96 \%)$ accepted.

Main outcome measures-Information obtained from hospital records, genetic analysis, and postmortem findings.

Results-166 fetal anomalies occurred; 140 were detected at 19 weeks (sensitivity $85 \%$; specificity $\mathbf{9 9 . 9 \% ) . ~ I n ~} 27$ cases fetuses were shown to have severely crippling or lethal abnormalities; termination of pregnancy was requested in 25 . Early diagnosis influenced timing and place of delivery in babies with severe cardiac or gastrointestinal anomalies.

Conclusion-Scanning at 19 weeks with availability of termination can reduce perinatal morbidity and mortality. Scanning can be performed in a general ultrasound department with adequate counselling
\end{abstract} coth Carole A Luck, consultant radiologist facilities and close cooperation between radiographers, midwives, obstetricians, paediatricians, and the radiologist.

\section{Introduction}

The value of obstetric scanning at 19 weeks' gestation has been assessed in major tertiary referral centres, ${ }^{12}$ but a prospective study that includes centres which are not tertiary referral centres is needed. ${ }^{3}$ Only one study on an unselected population has been recorded, and this emphasised the need for more data to be collected. ${ }^{4}$ The purpose of the present study is to redress this balance and assess the value of 19 week ultrasound scanning in such a population.

A report of the Royal College of Physicians states that routine scanning is offered to pregnant women at only a few centres; in most areas it is available only to women in recognised risk groups. The report continues: "there is good evidence that, with an appropriately organised obstetric ultrasound service, most structural malformations could be detected."s

Most analyses agree that screening and prenatal diagnosis programmes are wanted by the population and offer major medical and financial advantages. ${ }^{5}$ The investment required is modest and will conserve NHS resources. Studies show that where risks exist, 
expectant mothers want the tests. ${ }^{6}$ However, $90 \%$ of abnormalities occur in fetuses born to mothers not known to have risk factors.

No recognisable harm is known to result from using ultrasound at diagnostic levels, but some centres are unwilling to perform scanning in the present litigious climate, fearing legal action for a missed anomaly.

\section{Subjects and methods}

Over four years between 1988 and 1991 the results of routine 19 week obstetric scans on mothers attending Heatherwood Hospital were monitored. Of the 8849 patients offered scans, 8523 accepted, giving a compliance rate of $96 \%$. The catchment area included a new town, Bracknell, the surrounding villages, and parts of Windsor, Maidenhead, and Slough.

The ultrasound department during this time comprised two scanning rooms, one containing (since 1984) a Siemens Sonoline SL. This has $3.5 \mathrm{MHz}$ and $5 \mathrm{MHz}$ sector probes, a $3.5 \mathrm{MHz}$ linear probe and $\mathrm{M}$ mode, a multiformat imaging system, and a video recorder. The other room contained (since 1988) an Ultramark IV ATL with $7.5 \mathrm{MHz}$ and $3.5 \mathrm{MHz}$ linear array probes and $3.5 \mathrm{MHz}$ and $5 \mathrm{MHz}$ sector and $5 \mathrm{MHz}$ transvaginal probes. This machine has a thermoprinter and video recorder. The department has a single office and a waiting room and is near the obstetric department. The ultrasound department is also responsible for general scanning, and its workload is well in excess of 10000 patients a year.

Scans were performed by two full time and one half time radiographer, all of whom had held the diploma in medical ultrasound for at least four years and exclusively performed obstetric scans. Patients with risk factors or raised maternal serum $\alpha$ fetoprotein concentrations or who had suspicious findings on the initial scan were then scanned by the radiologist (CAL). This scan was performed within three hours of obstetric counselling or of the initial suspicion of abnormality. Before any scans were performed, the obstetrician discussed the implications with the patients so that they realised the situation in which they might be placed and the dilemmas which they might face in terms of possible outcome. This was reiterated by the radiographer before the scan. No independent assessment of the scans was made.
At 12-14 weeks' gestation a "booking" scan was performed. This takes five minutes and enables accurate dating for maternal serum $\alpha$ fetoprotein measurements and the 19 week scan. The 19 week scan determines growth parameters, head and abdominal circumference, biparietal diameter, femoral length, and sometimes general limb length. It consists of a full fetal anatomy scan, including a four chamber view of the heart.

Results were recorded in close cooperation with obstetricians and paediatricians. Maternal serum $\alpha$ fetoprotein concentrations were also recorded. Cases with fetal cardiac anomalies and some other complex anomalies were referred to tertiary centres. Amniocentesis was performed at Heatherwood; cordocentesis and other invasive techniques, such as fetal urine sampling, were performed at the tertiary referral centre.

Comments were made in the notes on the effect of anomalies on the parents' attitude and that of the extended family. A note was also made if the 19 week scan was particularly difficult-for example, because of maternal obesity or multiple pregnancy. Each radiographer could identify her own work and results.

Second trimester termination was by prostaglandin induction, and a postmortem examination was agreed in the majority of cases. Genetic material was analysed at the University of Oxford.

\section{Results}

Abnormality detection is analysed by organ systems (tables I-VII). Each table is divided into abnormalities detected, those undetected and the affect on outcome.

Analysis of 8523 ultrasound scans at 19 weeks detected 140 anomalies. A total of 166 anomalies were recorded at delivery or in the first week of life. The incidence of anomalies in this unselected population is $1.9 \%$, including relatively minor renal abnormalities. The detection rate by ultrasonography (sensitivity) is thus $85 \%$, with a specificity of $99.9 \%$.

All serious renal (table I) and central nervous system (table VI) abnormalities were detected. All but one gastrointestinal abnormality was detected (table II). Only two out of the five diaphragmatic hernias (table III) were diagnosed at 19 weeks, and the major lung abnormality was undetected. In the case of skeletal abnormalities (table IV), the major structural anomalies

TABLE I - Abnormalities of renal system detected by ultrasound scanning at 19 weeks' gestation

\begin{tabular}{|c|c|c|c|}
\hline Disorder & $\begin{array}{c}\text { No } \\
\text { detected }\end{array}$ & $\begin{array}{l}\text { No not } \\
\text { detected }\end{array}$ & Outcome \\
\hline Renal agenesis & 2 & & Termination of pregnancies \\
\hline Posterior urethral valve & 4 & & $\begin{array}{l}1 \text { Severe abnormality; termination of pregnancy } \\
3 \text { Valves seemed to disperse during pregnancy, but babies had renal } \\
\text { cortical damage; all three had normal deliveries }\end{array}$ \\
\hline Unilateral renal cystic dysplasia & 4 & & $\begin{array}{l}\text { Normal deliveries; confirmed at delivery; non-functioning kidney in } \\
\text { each case }\end{array}$ \\
\hline Bilateral hydronephrosis; pelvic diameter $>10 \mathrm{~mm}$ due to bilateral pelvis-ureteric function obstruction & 1 & & $\begin{array}{l}\text { Normal delivery. Great Ormond Street Hospital randomised } \\
\text { trial-given antibiotics only }\end{array}$ \\
\hline Unilateral hydronephrosis; pelvic diameter $>10 \mathrm{~mm}$ & 6 & & $\begin{array}{l}\text { All normal deliveries; under care of paediatrician and urologist; some } \\
\text { children have had surgery }\end{array}$ \\
\hline Unilateral hydronephrosis; pelvic diameter $>6-10 \mathrm{~mm}$ & 88 & & $\begin{array}{l}\text { Under care of paediatricians; findings did not affect obstetric } \\
\text { management }\end{array}$ \\
\hline
\end{tabular}

Sensitivity $100 \%$, specificity $100 \%$, positive and negative predictive values $100 \%$.

TABLE II - Abnormalities of gastrointestinal system detected by ultrasound scanning at 19 weeks' gestation

\begin{tabular}{|c|c|c|c|}
\hline Disorder & $\begin{array}{c}\text { No } \\
\text { detected }\end{array}$ & $\begin{array}{c}\text { No not } \\
\text { detected }\end{array}$ & Outcome \\
\hline Gastroschisis & 2 & & Both alive; delivered in specialist centres; operated after delivery \\
\hline Exomphalos & 2 & & $\begin{array}{l}1 \text { Termination of pregnancy (additional anomalies) } \\
1 \text { Delivered at specialist centre; operated after delivery }\end{array}$ \\
\hline Mesenteric cyst & 1 & & Resolved during pregnancy \\
\hline Duodenal atresia & 1 & & $\begin{array}{l}\text { Karyotyped (Down's syndrome); proceeded with pregnancy; delivered at Heatherwood; surgery after delivery at } \\
\text { Great Ormond Street }\end{array}$ \\
\hline ?Oesophageal atresia & 1 & & Normal on subsequent scans; false positive result; child normal at delivery \\
\hline Distal oesophageal atresia and tracheo-oesophageal fistula & & 1 & No subsequent scans as clinically normal pregnancy; fetus and amniotic fluid volume appeared normal at 19 weeks \\
\hline
\end{tabular}

Sensitivity $86 \%$, specificity $99 \cdot 9 \%$, positive predictive value $100 \%$, negative predictive value $99 \cdot 9 \%$. 
were detected, but less obvious anomalies affecting face, hands, and feet were not always found. Nine major cardiac anomalies (table VI) were diagnosed at 19 weeks and two further such anomalies at late booking scans ( 24 weeks).

Foreknowledge of the maternal serum $\alpha$ fetoprotein concentration did not seem to alter the detection rate of anomalies. Most cases with open neural tube defects had not had maternal serum $\alpha$ fetoprotein results at the time of scanning. One of the fetuses with an abdominal wall defect was associated with a raised maternal serum $\alpha$ fetoprotein concentration; results in the other were unknown at the time of scanning.

The false positive rate was low because all suspected anomalies were scanned twice by the radiographers and then by the radiologist. Video recordings of susperted anomalies were extremely useful, both in the anaiysis of the anomaly and for subsequent teaching.

\section{Discussion}

The Royal College of Obstetrics and Gynaecology working party's report states that the information gained by routine scanning at 19 weeks may help to reduce infant handicap and perinatal mortality. ${ }^{7}$ In this series, most parents faced with a severely crippling or lethal disorder asked for termination of pregnancy. In the case of less severe anomalies, arrangements were made for early treatment, either surgical or medical.

Three male fetuses with a diagnosis of posterior urethral valves at 19 weeks and apparent subsequent dispersal were recorded. The diagnoses were based on bilateral hydronephroses and hydroureters and a distended bladder. There was no evidence of bladder emptying over half an hour and on two attendances; liquor volume was normal. All three fetuses were subjected to serial scans, and in all three spontaneous regression of the distended bladder with voiding was noted in the third trimester. The kidneys remained dilated, with reduced renal cortical width. After delivery one child was found to have massive vesicoureteric reflux, but no valves were seen on a micturating cystourethrogram. One child had mild dilatation of the collecting systems, no reflux, but a thick walled bladder and a normal stream on urethrography. The other child had small, dysplastic kidneys and no reflux, but a thick walled bladder and dilatation of the proximal urethra and a good voiding stream. A similar case has been reported recently. ${ }^{8}$

Only two out of the five diaphragmatic hernias were detected at 19 weeks, but the others were detected on growth scans later in pregnancy. This is in keeping with findings in other centres.

Major, life threatening skeletal abnormalities were detected but the most subtle anomalies, involving digits and face, were not detected. The study has created an awareness that should improve the detection rate. Of the two cases of achondrogenesis recorded, one was diagnosed on the basis of virtually absent ossification of the vertebral bodies together with normal

TABLE III - Abnormalities of lungs and diaphragm detected by ultrasound screening at 19 weeks' gestation

\begin{tabular}{|c|c|c|c|}
\hline Disorder & $\begin{array}{c}\text { No } \\
\text { detected }\end{array}$ & $\begin{array}{l}\text { No not } \\
\text { detected }\end{array}$ & Outcome \\
\hline Diaphragmatic hernia at 19 weeks & 2 & $\begin{array}{l}3 \\
1\end{array}$ & $\begin{array}{l}1 \text { Termination of pregnancy } \\
1 \text { Normal karvotype, but died at } 1 \text { day after normal delivery } \\
\text { All detected hefore delivery on growth scans: } 1 \text { at } 28 \text { weeks, } 1 \text { at } 32 \text { weeks, } 1 \text { at } 38 \text { weeks; all went to } \\
\text { surgery anci were doing well. } 2 \text { Delivered at Heatherwood, the other successfully delivered elsewhere } \\
\text { Normal on subsequent scans; normal at delivery (false positive result) }\end{array}$ \\
\hline Cystic adenomatoid malformation of lung (right upper lobe) & & 1 & Normal delivery; respiratory distress; transferred to Great Ormond Street for surgery; now well \\
\hline
\end{tabular}

Sensitivity $33 \%$, specificity $99 \cdot 9 \%$, positive predictive value $66 \cdot 6 \%$, negative predictive value $99 \cdot 9 \%$.

TABLE IV-Skeletal abnormalities detected by ultrasound scanning at 19 weeks' gestation

\begin{tabular}{|c|c|c|c|}
\hline Disorder & $\begin{array}{c}\text { No } \\
\text { detected }\end{array}$ & $\begin{array}{l}\text { No not } \\
\text { detected }\end{array}$ & Outcome \\
\hline Achondrogenesis & 2 & & Terminations of pregnancy \\
\hline Hypoglossia or hypodactyly & 1 & & Termination of pregnancy; previous chorionic villus sampling \\
\hline Severe talipes & 2 & 1 & $\begin{array}{l}\text { Normal delivery; died at } 1 \text { day; previous chorionic villus sampling } \\
\text { Normal delivery; orthopaedic referral }\end{array}$ \\
\hline Marked kyphoscoliosis & 1 & & Normal delivery; orthopaedic referral \\
\hline Apert's syndrome, syndactyly and cleft palate present & & 1 & Normal delivery; paediatric referral \\
\hline Trisomy 13 (low set ears and incurved little and ring fingers bilaterally) & & 1 & Normal delivery; died at 3 months \\
\hline Abnormal chromosome 4Q (long fingers and rocker bottom feet) & & 1 & Paediatric referral \\
\hline
\end{tabular}

Sensitivity $60 \%$, specificity $99.9 \%$, positive predictive value $100 \%$, negative predictive value $99 \cdot 9 \%$.

Until 1990 fine details of digits and fetal face were not scanned in detail. At that time we detected a possible association between two cases of hypoglossia/hypodactyly and previous chorionic villus sampling. Face and digits were thenceforth examined in more detail. Minor syndactyly and hare lips have not been detected.

TABLE V-Cardiac anomalies detected by ultrasound scanning at 19 weeks' gestation

\begin{tabular}{|c|c|c|c|}
\hline Disorder & $\begin{array}{c}\text { No } \\
\text { detected }\end{array}$ & $\begin{array}{l}\text { No not } \\
\text { detected }\end{array}$ & Outcome \\
\hline \multirow[t]{3}{*}{ Hypoplastic left heart } & 4 & & Termination of pregnancy \\
\hline & & 3 & 2 died at 2 days; 1 detected on 30 week growth scan; normal delivery; died at 3 days \\
\hline & (2) & & Detected at late booking at 24 weeks; normal deliveries; both died at 2 days \\
\hline Hypoplastic right heart & & 1 & Maternal serum $\alpha$ fetoprotein raised; died at 3 days \\
\hline Complex cardiac anomalies & 2 & & Both karyotyped (Down's syndrome); terminations of pregnancy \\
\hline Total anomalous inflow and outflow & & 1 & A twin; died at delivery \\
\hline Atrial septal defect and ventricular septal defect & 2 & & Cardiological care; normal delivery \\
\hline Large ventricular septal defect & & 1 & Cardiological care; normal delivery \\
\hline Atrial solitus & & 1 & Stillborn (a twin) \\
\hline Cardiac tumour & 1 & & Intrauterine death \\
\hline Truncus arteriosus & & 1 & Normal delivery; died at 1 day \\
\hline Coarctation of the aorta ( 1 fetus had cystic hygroma) & & 2 & Normal delivery; both had surgery \\
\hline Fallot's tetralogy & & 1 & Normal delivery; surgery \\
\hline Transposition of the great arteries & & 2 & Normal delivery; surgery \\
\hline Transposition of the great arteries and tricuspid stenosis & & 1 & Normal delivery; surgery \\
\hline Pulmonary atresia & & 1 & Normal delivery; died at 1 day \\
\hline Pulmonary atresia; double outlet ventricle & & 1 & Normal delivery; surgery \\
\hline ?Abnormal four chamber view & 2 & & False positive results; normal at 24 and 28 week scans performed at Guy's Hospital \\
\hline
\end{tabular}

Sensitivity $36 \%$, specificity $99 \cdot 9 \%$, positive predictive value $81 \cdot 8 \%$, negative predictive value $99 \cdot 8 \%$. 


\begin{tabular}{lccl}
\hline Disorder & No detected & $\begin{array}{c}\text { No not } \\
\text { detected }\end{array}$ & Outcome \\
\hline Anencephaly & $\begin{array}{c}7 \\
\text { Meningocele encephalocele }\end{array}$ & Termination of pregnancy in all seven cases \\
$\begin{array}{l}\text { Spina bifida and Arnold Chiari malformation } \\
\text { Spina bifida and omphalocele }\end{array}$ & 15 weeks) & Termination of pregnancy \\
Holoprosencephaly & 1 & $\begin{array}{c}\text { Termination of pregnancy } \\
\text { Termination of pregnancy }\end{array}$ \\
Bilateral choroid plexus cysts & 1 & Termination of pregnancy \\
& 16 weeks) & 1 & $\begin{array}{c}\text { Persisted at 24 weeks; both normal at delivery, } 1 \text { with normal karyotype, } 1 \text { with no } \\
\text { intervention }\end{array}$ \\
\hline
\end{tabular}

Sensitivity $100 \%$, specificity $100 \%$, positive and negative predictive values $100 \%$.

One fetus with hydrocephaly and spina bifida was a late booking first seen and detected at 26 weeks.

TABLE VII - Miscellaneous findings of ultrasound scanning at 19 weeks' gestation

\begin{tabular}{|c|c|c|c|}
\hline Disorder & $\begin{array}{c}\text { No } \\
\text { detected }\end{array}$ & $\begin{array}{l}\text { No not } \\
\text { detected }\end{array}$ & Outcome \\
\hline Fetal ascites $++($ mother had $\beta$ thalassaemia $)$ & 1 & & Normal karyotype; serial scans; normal at delivery \\
\hline Cystic hygroma in one twin & 1 & & Caesarean section; abnormality confirmed at delivery (normal karyotype); both twins well \\
\hline Huge cystic placenta; intrauterine growth retardation in fetus & 1 & & $\begin{array}{l}\text { Baby small for dates, but otherwise normal; normal karyotype of placenta and baby; caesarean } \\
\text { section at } 35 \text { weeks }\end{array}$ \\
\hline Baby with short arm on chromosome 4 ; microcephaly; mild cleft palate & & 1 & Not detected; died after delivery \\
\hline
\end{tabular}

skull ossification and short limbs. The other case was diagnosed as a complex skeletal dysplasia with short limbs and normal calvarium but abnormalities of the cervicothoracic spine. The specific diagnosis was made at postmortem examination.

In one case with a detected complex cardiac anomaly the maternal serum $\alpha$ fetoprotein concentration was known to be raised at the time of the scan, and it was known to be raised in one other case where the anomaly remained undetected. Of the 15 major anomalies undetected, eight infants died soon after delivery and six survived surgery. In the undetected group, two fetuses were from separate twin pregnancies, and in another maternal obesity was commented on. It should be noted that defects consistently missed in most series include atrial septal defect, small or moderate ventricular septal defect, aortic stenosis, pulmonary stenosis, total anomalous venous drainage, and aortic coarctation. ${ }^{10}$ Examination of the heart at the beginning of this study involved an assessment of the four chamber view only. This established the presence of two symmetrical ventricles and atria. As the radiographers became more experienced, inflow and outflow tracts were examined, leading to a higher rate of anomaly detection. The two false positive results occurred in the first six months of the programme. As a result of these findings more time is now devoted to the cardiac scan. One more radiographer has been employed full time and a further machine (Acuson 128 $\mathrm{XP} / 3$ ) purchased, with a new room to house it.

Diagnostic accuracy has increased in all systems along with the experience of the radiographer and this has been enhanced by experience with paediatric scans. It is advantageous for general ultrasound examinations to be performed in the same department as obstetric scans. This allows radiographers to watch postnatal scans on infants they have scanned antenatally.

Several benefits have accrued from this ultrasound screening programme. These are both medical and financial. Informed parents have been prepared for problems to come, and appropriate delivery sites have been arranged where necessary. Antenatal diagnosis has been found to reduce the number of postnatal investigations and, hopefully, has avoided a late clinical presentation. For example, moderate hydronephrosis has been confirmed after delivery and the baby then put on prophylactic antibiotics, in the hope of avoiding urinary tract infections and renal scarring in the future.

Tertiary referral has been found to be of particular benefit in the case of severe disabling conditions. This has enabled cordocentesis to be performed and, if appropriate, the fetus to be treated. It also gives the parents the benefit of experts' knowledge of rare conditions, allows further counselling, and helps parents to realise that they are not alone in producing a fetus with an abnormality.

The detection of an anomaly with the offer of termination for those fetuses with severe crippling deformities would seem to be cost effective. On the basis of the Department of Health and Social Security's estimate of the cost of maintaining a severely crippled infant for 40 years, termination of pregnancy in these cases was estimated in 1984 to result in a gross saving of $£ 2238000$ for an expenditure of $£ 120000$ on routine scans. ${ }^{7}$ Equally, early treatment of some conditions, such as those that cause potential renal failure, would have some cost benefit.

It is vital that staff involved in the screening programme, radiographers, radiologists, obstetricians, midwives, and paediatricians work closely together to facilitate good communication with and counselling of the patient. A counselling room must be available in the department for this purpose. Learning of the diagnosis of an anomaly, particularly a lethal abnormality, is devastating, and news of a minor anomaly can alter the parental outlook - the fetus then becomes "a patient"-and affect prenatal bonding. Parents should realise that screening has been performed to detect unknown risks, for the benefit of the mother and the fetus, and the fetus is a person in the eyes of the ultrasonologist. ${ }^{11}$ The medical staff must be aware of the ethical dimensions of obstetric ultrasound. ${ }^{12}$

\section{CONCLUSIONS}

Routine ultrasound scanning at 19 weeks is recommended to all obstetric departments if performed by trained, experienced ultrasonographers in the right environment. Full radiological, obstetrical, and paediatric support is essential. Such scanning has a relatively high level of accuracy in the diagnosis of fetal anomalies, cardiac anomalies being the most difficult to detect. It would seem to be cost effective and, in this study, was found to alter obstetric management both in timing and place of delivery.

My sincere thanks are due to Mr N R A Trickey and Miss Jane Spring for allowing their patients to be used in this study; also to Margaret Goodwin and Jean Standsbridge for helping to collect the data, and to Margaret Norton for typing the 
paper. Particular thanks for the enthusiasm and dedication of the radiographers Sharron Cox, Jane Mattock, Marie Ayears Jackie Scrutton, and Alison Baker, and to my husband, John, for his unfailing support and encouragement.

1 Campbell S, Pearce JMF. The prenatal diagnosis of foetal strictural anomalics by ultrasound. Clin Obstet Gynaecol 1983;10:475-506.

2 Campbell S, Smith P. Routine screening for congenital anomalies by ultrasound. In: Rodeck CH, Nicolaides K. Prenatal diagnosis. London Royal College of Obstetricians and Gynaecologists; Chichester: Wiley, 1984:325-30.

$3 \mathrm{McNay}$ M. Clinical considerations in screening for foetal abnormalities. British Medical Society Ultrasound Bulletin. 1991;No 63:23.

4 Chitty LS, Hunt GH, Moore J, Lobb MO. Effectiveness of routin ultrasonography in detecting fetal structural abnormalities in a low risk population. BMF 1991;303:1165.

5 Roval College of Physicians. Report: prenatal diagnosis in genetic screening. London: RCP, 1989:14-5.

6 Thomson P. Where risks exist expectant mothers want tests. The Times 1991 Dec 2:15.

7 Royal College of Obstetricians and Gynaecologists. Working party report on routine ultrasound examination in pregnancy. London: RCOG, 1984:10.

8 Hecher K, Henning K, Spernol R, Szalay S. Spontaneous remission of urinary tract obstruction and ascites in a foetus with posterior urethral valves. Ultrasound in Obstetrics and Gynaecology. 1991;1:426-43.

9 Benacerraf BR, Adzick NS. Foetal diaphragmatic hernia; ultrasound diagnosi and clinical outcome. Am f Obstet Gynecol 1987;156:573-6.

10 Crawford DC, Chita SK, Allan LD. Prenatal diagnosis of congenital heart disease: factors affecting obstetric management and survival. Am F Obstet Gynecol 1988;159:352-6.

11 Hansman $M$. The foetus as a patient: the foetus as a person? Ultrasound in Obstetrics and Gynaecology 1991;1:305-6.

12 Chervenak FA, McLullogh LB. Ethics, an emerging subdiscipline of obstetric ultrasound, and its relevance to routine obstetric scanning. Ultrasound in Obstetrics and Gynaecology 1991;1:18-20.

(Accepted 18 March 1992)

\title{
Toxicity of norpethidine in sickle cell crisis
}

\author{
B J Pryle, H Grech, P A Stoddart, R Carson, \\ T O'Mahoney, F Reynolds
}

Department of

Anaesthesia, St Thomas's

Hospital, London SE1 7EH

B J Pryle, lecturer

P A Stoddart, registrar

R Carson, laboratory scientific

officer

T O'Mahoney, research

assistant

F Reynolds, reader in

pharmacology applied to

anaesthesia

\section{Department of}

Haematology, St Thomas's

Hospital, London SE1 7EH

$\mathrm{H}$ Grech, lecturer

Correspondence to:

Dr Reynolds.

BMf 1992;304:1478-9
Over six months we observed eight episodes of focal and generalised seizures in patients with sickle cell disease who had been treated with high doses of intramuscular pethidine. Recently Mitchell et al reported the death during grand mal seizure of a man in sickle cell crisis after two days of taking high dose pethidine. ${ }^{1}$ Norpethidine, an N-demethylated metabolite of pethidine, was identified as neurotoxic by Batterman in 1957, and subsequent studies have documented the adverse consequences of norpethidine accumulation..$^{23}$ Although isolated norpethidine concentrations have been measured at random in patients with sickle cell disease, we have found no systematic study. Our objective was to measure serum pethidine and norpethidine concentrations after multiple doses of pethidine to assess the extent of their accumulation and to identify their relation with seizures.

\section{Patients, methods, and results}

Fourteen AfroCaribbean patients with a diagnosis of sickle cell crisis who were receiving two hourly intramuscular pethidine gave verbal consent to give blood for analysis. Blood was taken immediately before and $15,30,60$, and 120 minutes after a pethidine injection. The patient's weight, serum urea and creatinine concentrations, most recent individual dose of pethidine, total dose in the previous 24 hours per kilogram body weight ( 24 hour pethidine dose), and total dose of pethidine during the crisis (total dose) were noted. Two additional patients who suffered grand ma seizures while receiving high dose pethidine treatment had blood samples taken shortly after the convulsions. Pethidine and norpethidine concentrations were measured by gas chromatography. ${ }^{4}$

Nine men and seven women of mean age 27 years (range 17-45) and mean weight $59 \mathrm{~kg}$ (range 50-70) were investigated. They had received two hourly intramuscular pethidine for between one and 35 days (mean seven, mode three). All except one had detectable concentrations of pethidine and norpethidine in the first sample. Mean (range) pharmacokinetic data for pethidine and norpethidine were: maximum measured plasma concentration $1.29(0.46-2 \cdot 8)$ and 0.72 $(0 \cdot 24-1 \cdot 86) \mu \mathrm{g} / \mathrm{ml}$; time to maximum concentration $37 \cdot 5(12-120)$ and $55(15-120) \mathrm{min}$; area under the curve of concentration against time curve 109 $(20 \cdot 5-243)$ and $66 \cdot 2(18-100) \mu \mathrm{g} . \mathrm{s} / \mathrm{ml}$. Maximum measured concentrations of norpethidine exceeded $1 \mu \mathrm{g} / \mathrm{ml}$ in four patients, three of whom had suffered a convulsion within a few hours of sampling. Two of these patients had been taking pethidine tablets at home before admission, and one had significant renal impairment (serum creatinine concentration $146 \mu \mathrm{mol} / \mathrm{l}$, normal range 50-100).

Linear regression analysis showed that the maximum measured concentration (figure) and area under the time concentration curve for norpethidine correlated significantly with the 24 hour pethidine dose $(r=0 \cdot 74$, $\mathrm{p}=\mathbf{0 . 0 0 1}$ for both). The relation was also significant for pethidine $(r=0.56, \mathrm{p}<0.05$ for both $)$. There was no

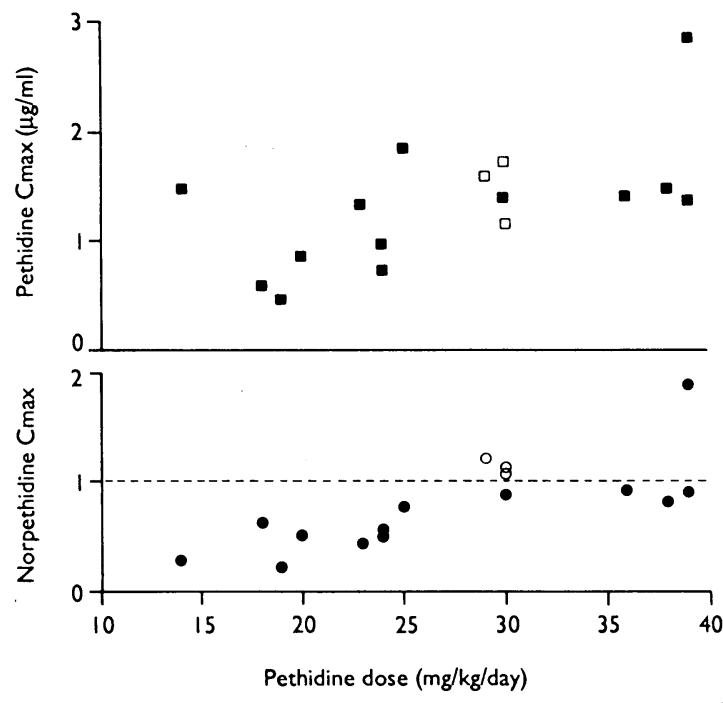

Maximum measured concentration of pethidine (square symbols) and norpethidine (round symbols) after intramuscular pethidine plotted against daily dose of pethidine in 16 patients. Open symbols represent the three patients who had convulsions

association between peak plasma pethidine concentration and seizures. There was no correlation between the total dose or last dose of pethidine and the maximum measured concentration or area under the time concentration curve for pethidine and norpethidine.

\section{Comment}

The results suggest that daily doses of pethidine greater than $25 \mathrm{mg} / \mathrm{kg}$ may be associated with toxicity (figure), particularly in the presence of renal impairment or if pethidine has been taken orally, when high first pass clearance results in rapid conversion to norpethidine. As the life expectancy of sickle cell patients increases, renal impairment becomes a more significant problem in older patients. The plasma half life of norpethidine with normal renal function is $14-20$ hours, which implies that norpethidine concentrations may take about three days to reach $90 \%$ of the final plateau value. As all but one of our patients had been receiving pethidine for three days or more, no correla- 